\title{
Gender Issue in COVID-19 Pandemic
}

\section{* Santoshi Giri ${ }^{1}$, Sitaram Khadka², Sushma Ranabhat ${ }^{3}$, Mariam Agha ${ }^{3}$}

${ }^{1}$ Nepal Public Health Research and Development Center, Kathmandu, Nepal

${ }^{2}$ Shree Birendra Hospital; Nepalese Army Institute of Health Sciences, Kathmandu, Nepal

${ }^{3}$ Punjab University College of Pharmacy, University of the Punjab, Lahore, Pakistan

*Corresponding Author: Santoshi Giri, Email: san.giri2008@gmail.com

\begin{abstract}
Since the first outbreak, COVID-19 has manifested itself as a serious public health threat with severe social and economic implications. Gender is an essential component that requires special attention and action in such crisis. This review is aimed at finding the gender-related issues amid COVID-19 pandemic that need to be considered and help stimulate related stakeholders to devise effective policies and actions.

Health, socio-economical and education, all domains of gender are viciously affected by this pandemic. Though men and women have the same prevalence, men with COVID-19 are more at risk of worse outcomes and death. Even though the direct impact of disease is observed significantly high in men, the secondary socio-economic impact is catastrophic in women and girls considering their status in society as they are systemically oppressed and vulnerable group of population. The pandemic will have a prolong effect on socioeconomic dynamics. Hardly achieved milestones on gender equality reached low, which will take long to bounce back. From this crisis, government and policy makers should take a lesson and formulate public health policies and measures to contain the epidemic that takes account of gender and its interactions with all areas of inequality.
\end{abstract}

Keywords: Female, COVID-19, Vulnerable populations, Severe acute respiratory syndrome coronavirus-2, Socioeconomic factors, Health policy

\begin{tabular}{|c|c|c|}
\hline \multicolumn{2}{|c|}{ Access this article Online } & Article Info. \\
\hline Quick Response Code & Website: & How to cite this article in Vancouver Style? \\
\hline & www.jkahs.org.np & $\begin{array}{l}\text { Giri S, Khadka S, Ranabhat S, Agha M. Gender Issue } \\
\text { in COVID-19 Pandemic. JKAH Journal of Karnali } \\
\text { Academy of Health Sciences 2020;3(2): 152-158 }\end{array}$ \\
\hline \& V V & $\begin{array}{l}\text { DOI: } \\
\text { https://doi.org/10.3126/ } \\
\text { jkahs.v3i2.31238 }\end{array}$ & $\begin{array}{ll}\text { Received } & : 11 \text { July } 2020 \\
\text { Accepted } & : 20 \text { August } 2020 \\
\text { Published Online } & : 21 \text { August } 2020 \\
& \\
\text { Conflict of Interest } & \text { : None } \\
\text { Source of Support } & : \text { None }\end{array}$ \\
\hline
\end{tabular}




\section{INTRODUCTION}

COVID-19 pandemic has affected every corner and every facet of the world. ${ }^{1}$ Besides the severe impact on health of all, the pandemic has a profound impact on socioeconomic dynamics. ${ }^{2}$ The lockdown approach adopted as a containment strategy has a vicious impact on the world economy with a rapid plunge in business, marketing, tourism, education, and other activities ${ }^{3}$ which have negative impact on psychosocial well-being of people. ${ }^{4}$ Pandemics and outbreaks have differential impacts on women and men owing to their exposure to risk factors, biological susceptibility to infection, interaction with other social determinants, and their social and economic implications. ${ }^{5}$

It is observed that the prevalence of COVID-19 is the same in men and women men are more likely to have worse outcomes and death. ${ }^{6,7}$ For example, the death rate of men in US is double the rate of women; In Western Europe $69 \%$ of all coronavirus deaths have been male. Similar patterns have been observed in China, Nepal, Pakistan, Bangladesh and many other countries. ${ }^{8}$

Though the primary impact of disease is observed significantly high in men, the indirect socioeconomic impact is very high in women and girls given the status of women in society. ${ }^{9}$ Considering the fact that women and girls are at higher risk of adverse health, social and economic impacts of COVID-19, The World Health Organization (WHO) has advised all countries to incorporate gender-focused approaches into their COVID-19 responses while formulating public health policies and actions for the containment of the pandemic. ${ }^{5}$

\section{METHODS}

Recently published literature like articles or news on COVID-19 and gender equality in databases like PubMed, Google Scholar, Science Direct, and related webpages were searched. We included relevant works published in the recent period of 2020 besides for the general explanation and terminologies. The terms 'COVID-19', 'gender issues in crisis', and 'COVID-19 and gender equality' were the key words used to search the articles. Related experts in the field were also consulted for further improvement of the article.

\section{HEALTH AND SOCIO-ECONOMIC IMPLICATIONS OF COVID-19}

\section{Insurgence in Gender Based Violence}

Gender Based Violence (GBV) includes rape, sexual assault, physical assault, forced marriage, restriction in resources and opportunities, abuse, and intimate partner violence..$^{10}$ Domestic, sexual, and gender-based violence surges during such crises as observed during the 2014-16 Ebola and 2015-16 Zika epidemics and it appears to be happening now. ${ }^{7}$ The world observed a spike in domestic, sexual, and gender-based violence during this quarantine period. Domestic violence reports and calls have increased by 33\% in Singapore, 30\% in Cyprus and France, and 25\% in Argentina since COVID-19 lockdown. ${ }^{11}$ WHO also reported escalation in domestic abuse calls across Europe. Similarly, developing countries like India, Brazil, Bangladesh, and Nepal also have reported a rise in domestic violence cases. United Nations Population Fund (UNFPA) estimates that continuation of lockdown for six months will add up to 31 million new cases of gender-based violence globally, with additional 15 million extra cases for every 3 months of lockdown. ${ }^{12}$

The contributing factors for upsurge in domestic violence are stress due to health and financial insecurity, cramped living conditions, isolation with abusers, restriction in movement, and empty public space. ${ }^{11}$

Another brutal form of violence that has magnified during this lockdown is rape..$^{13}$ In Nepal, 717 rape cases, 79 cases of child sexual abuses and 199 attempt-to-rape cases were reported during the lockdown period. ${ }^{14}$ Few cases of rape were also reported in quarantine centers. Similarly, Haryana Police, India recorded 66 rape cases, including 17 gang rapes; 62 abduction cases and 142 incidents of molestation in April, 2020. ${ }^{15}$ Likewise, murder cases are also witnessed frequently during these days of pandemic. In Haryana, India, a 30\% rise in dowry death was observed in April 2020 in comparison to that in April, 2019. ${ }^{15}$

Globally, four million girls are at risk of early and enforced marriage in the next two years as poverty caused by this pandemic will drive families to marry off 
their daughters early. ${ }^{16}$ The disruption in effort to end child marriage might potentially result in an additional 13 million child marriages taking place between 2020 2030 that otherwise could have been prevented. ${ }^{12}$

\section{Unemployment and Financial Crunches}

The position of women in the labor market is less secure in comparison to men, which will face prolonged dip as a result of this pandemic, therefore women are economically more vulnerable than men. ${ }^{17}$ Almost 25 million jobs could be lost worldwide as a result of COVID-19. ${ }^{18}$ The most vulnerable groups for lay-offs and job cuts are women, informal workers, migrants, youths, and the world's poorest population. ${ }^{19} \mathrm{UN}$-Women survey in Asia and the Pacific region showed that women are losing their livelihoods faster than men and have few alternative ways of income generation. ${ }^{20}$ In the United States (US), men's unemployment increased from 3.55 million in February to 11 million in April in 2020 while women's unemployment increased to 11.5 million from 2.7 million over the same period. ${ }^{21}$ During the crisis in Nepal, 1.6-2.0 million jobs are likely to be disrupted, either complete job loss or reduction in working hours and wages. ${ }^{22}$ In total, $24.3 \%$ of the 2018 female workforce, i.e., 631,000, are estimated to be at risk of being unemployed. ${ }^{22}$

Women are under increased burden of unpaid care of children and elderly, and household work due to job cut-off, social distancing measures, school closures, and distorted health systems. ${ }^{9,23}$ Prolonged quarantine intensifies pre-existing gender inequities and power hierarchies. ${ }^{24}$ In a study carried out in Nepal, more than $90 \%$ of the girls said their time is spend doing household chores and about 30\% inferred about the increment in work load during lockdown ${ }^{25}$

The statement given by International Labor Organization (ILO) regarding COVID-19 as a major labor market and economic crisis with substantial impact on people, not merely a global health crisis, is pertinent. ${ }^{18}$

\section{Compromised Sexual and Reproductive Health}

Women's sexual and reproductive health and rights are compromised during the pandemic. ${ }^{26}$ The COVID-19 pandemic has potentially catastrophic secondary impacts on the health of women and girls around the world. While preparing government and health sector to deal with pandemic, resources are reallocated for the crisis, thus sexual and reproductive health services including pregnancy care; contraceptives; and safe abortion are likely to be scaled back. ${ }^{27}$ This will result in an increased risk of maternal mortality, unintended pregnancies, and other adverse sexual and reproductive health outcomes among women and girls. A study carried out in Nepal observed 52.4\% reduction in institutional delivery before and during lockdown. ${ }^{28}$ Similarly, spike in maternal mortality rates in West Africa due to lack of basic obstetric care has been reported. ${ }^{29}$

Continuation of lockdown for 6 more months restricts 47 million women in 114 low- and middle-income countries from accessing modern contraceptives, resulting into 7 million unintended pregnancies. ${ }^{12}$ Additional 2 million women may not be able to use modern contraceptives for every 3 months of the lockdown. ${ }^{12}$

\section{Increased Risk and Vulnerability}

Globally, women make up $70 \%$ of all health and social-services front liners. ${ }^{30}$ Consequently, they are at high risk of being infected owing to their frequent exposure to patients. In some countries, COVID-19 infections among female health workers are very high than that of their male counterparts like in Spain, Italy, and the US; $75.5 \%, 69 \%$, and 73\%, COVID infected health workers were women as of April $2020 .^{8}$

\section{Impact on Mental Health}

The pandemic is having a significant impact on people's mental health. About $33 \%$ of adults in US, $26 \%$ in Canada and UK, 24\% in France, and 23\% in Australia and New Zealand reported that their mental health had suffered due to the pandemic. ${ }^{31}$ Data on the mental health issues of women as such is not available. However, in case of pregnant women, in normal condition, $10 \%$ suffer from mental disorder, primarily depression which is about $16 \%$ in developing countries ${ }^{32}$ which might see rapid upsurge. The repercussion of the COVID-19 pandemic on mental health on pregnant women is a prime public health concern, which requires appropriate and timely health care support. ${ }^{33}$ Pregnant women are also at risk of psychological problems due to public health strategies like social distancing not only at the risk for medical related issues. ${ }^{34,35}$

Not only pregnant women, a significant proportion of female population might have mental health issues due to work frustration as closure of schools and 
daycare centers adds on to the plight of the mothers who are already laden with household chores and child care duties. Economic difficulties intensify the misery causing anxiety, stress, or depression. ${ }^{36}$ In a study carried out by Mercy crops in Nepal $56 \%$ of the girls said that they were dealing with psychological stress due to the lack of regular activities. ${ }^{25}$

International Association for Suicide Prevention (IASP) observed a significant increase on suicide in Pakistan and all over the world. ${ }^{37}$ Soaring suicide rates are actually attributed to the falling economy that takes toll on mental health. ${ }^{38}$ Isolation, anxiety, fear of infection, uncertainty, and financial crunches may lead to the development of mental health disorders or exacerbate the pre-existing psychiatric disorders. ${ }^{39}$ Stress-related psychiatric conditions are associated with suicidal behavior. ${ }^{38}$ The suicide cases in Nepal increased by $6 \%$ in women and $41 \%$ in girls during lockdown. ${ }^{14}$

\section{Upsoar in Hoax Calls and Cyber Bullying}

Some studies showed that hoax calls and cyber bullying have increased in many folds since lockdown. ${ }^{40}$ Due to stay-at-home strategy, people spend more time on phone and internet as the only way to connect with outside world. ${ }^{40,41}$ Analysis of millions of websites, popular teen chat sites, and gaming platforms found out that there is $900 \%$ increment in hate speech directed towards Chinese people, a $40 \%$ rise in online toxicity between teens and children, and $70 \%$ increase in hate between kids and teens during online chats. ${ }^{42}$ Children and girls are at high risk of cyber bullying.

\section{Obstacles in Education}

The COVID-19 pandemic has severely disrupted education systems affecting nearly 1.6 billion students in more than 190 countries across all continents. ${ }^{43}$ Crisis aggravated pre-existing disparities in the education sector by decreasing the opportunities for the most vulnerable group like girls, those living in poverty, refugees, and persons with disabilities.

School closures make girls and young women more prone to child marriage, early pregnancy, and genderbased violence. All of which lessen their possibility of continuing their education. ${ }^{43}$ The economic impact will increase dropout rate as millions will be pushed into severe poverty. Studies have shown that children from poorest households are significantly less likely to complete primary and lower secondary education than those in the richest. ${ }^{44}$

\section{SWOT ANALYSIS}

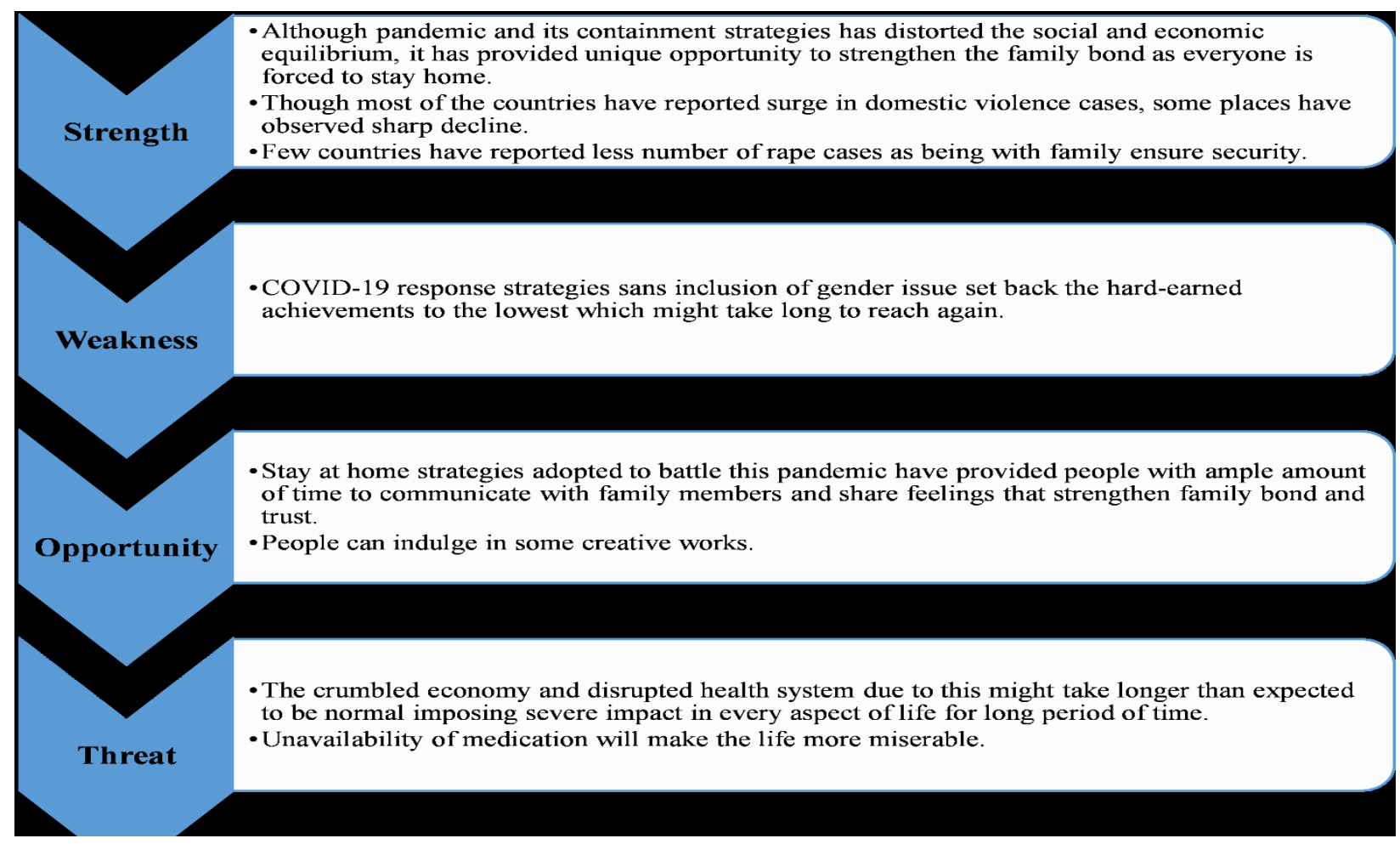

Figure 1: SWOT Analysis of COVID-19 and Gender 


\section{CONCLUSION}

COVID-19 has established itself as a serious public health threat with stark social and economic consequences since its outbreak. It is essential to deal with gender issues in such crisis as it requires special attention and action where prevailing disparities are profound. Such pandemics worsen the condition. The pandemic has affected all domains of gender issue be it health, economy, and education.

All forms of gender-based violence have increased during the pandemic. Sexual and reproductive health of women is compromised. Very hardly achieved milestones in sexual and reproductive health like institutional delivery and improved maternal and infant mortality rate have taken a dip plunge. Economic slowdown and job-cuts have taken a toll on mental health. Increase in mental health issues is evident. Prolonged quarantine amplifies preexisting gender inequities and pushed women back to the phase of unpaid care and domestic work. More leisurely time and restricted movement increased the risk of children and girls to be a victim of cyber bullying, harassment, and hoax calls. School closures make girls and young women more susceptible to child marriage, early pregnancy, and gender-based violence, decreasing their chance of continuing their education.

From this crisis, everyone is required to take a lesson and develop public health policies and measures that take account of gender so that the issues are dealt on time more efficiently.

\section{REFERENCES}

1. The Coronavirus Pandemic Timeline from December 2019 until Now [Internet]. OH\&S. 2020. Accessed August 18, 2020. [Link]

2. COVID-19 Socio-economic impact. UNDP. 2020. Accessed August 18, 2020. [Link]

3. Ozili PK, Arun T. Spillover of COVID-19: Impact on the Global Economy. 2020; [Google Scholar] [Link]
4. Mackolil J, Mackolil J. Addressing psychosocial problems associated with the COVID-19 lockdown. Asian J Psychiatr. 2020 Jun;51:102156. htps://doi.org/10.1016/j. ajp.2020.102156 [Google Scholar][PubMed]

5. Gender and COVID-19: advocacy brief. WHO. Published 2020. Accessed August 15, 2020. [Link]

6. Jin J-M, Bai P, He W, et al. Gender Differences in Patients With COVID-19: Focus on Severity and Mortality. Front Public Heal. 2020;8:152. https://doi.org/10.3389/fpubh.2020.00152 [PubMed] [Google Scholar]

7. What the COVID-19 pandemic tells us about gender equality. World Economic Forum. Published 2020. Accessed August 15, 2020. [Link]

8. COVID-19: Emerging gender data and why it matters. UNWomen. Accessed August 15, 2020. [Link]

9. Caring in the time of COVID-19: Gender, unpaid care work and social protection. unicef. org. 2020. Accessed August 18, 2020. [Link]

10. Sanjel S. Gender-based violence: a crucial challenge for public health. Kathmandu Univ Med journal. 2013;11(2):179-84. https:// doi.org/10.3126/kumj.v11i2.12499. [Google Scholar][PubMed]

11. How COVID-19 Impacts Women and Girls. UNWomen. Published 2020. Accessed August 15, 2020. [Link]

12. New UNFPA projections predict calamitous impact on women's health as COVID-19 pandemic continues. UNFPA. Published 2020. Accessed August 15, 2020. [Link]

13. Unicef Global COVID-19 Situation Report No. 6. Unicef. 2020. Accessed August 18, 2020. [Link]

14. Women, Children and Senior Citizen Service Directorate. CID Nepal Police. Published 2020. Accessed August 15, 2020. [Link] 
15. Haryana Police. Published 2020. Accessed August 15, 2020. [Link]

16. Coronavirus could put 4 million girls at risk of child marriage. World Economic Forum. Published 2020. Accessed August 15, 2020. [Link]

17. Policy Brief: The Impact of COVID-19 on Women. UN. 2020.Accessed August 18, 2020. [Link]

18. COVID-19: Protecting workers in the workplace. ILO. Published 2020. Accessed August 15, 2020. [Link]

19. Impact of COVID-19 on informal workers. FAO. 2020. Accessed August 18, 2020. [Link]

20. Surveys show that COVID-19 has gendered effects in Asia and the Pacific. UNWomen. Published 2020. Accessed August 15, 2020. [Link]

21. The Employment Situation- July 2020. BLS, USDL. Published 2020. Accessed August 15, 2020. [Link]

22. COVID-19 labour market impact in Nepal. ILO. Published 2020. Accessed August 15, 2020. [Link]

23. Power K. The COVID-19 pandemic has increased the care burden of women and families. Sustain Sci Pract Policy. 2020;16(1):67-73. https://doi.org/10.1080/15487733.2020.177656 1. [Google Scholar]

24. Sexual and gender-based violence during COVID-19: lessons from Ebola. The Conversation. 2020. Accessed August 18, 2020. [Link]

25. Impact of Lockdown: Psychosocial Distress and Safeguarding Issues among Stem II Girls. Mercy Corps. 2020. Accessed August 18, 2020. [Link]

26. COVID-19 pandemic cuts access to sexual and reproductive healthcare for women around the world. IPPF. 2020. Accessed August 18, 2020. [Link]
27. COVID-19: A Gender Lens. UNFPA. 2020. Accessed August 18, 2020. [Link]

28. KC A, Gurung R, Kinney M, et al. Effect of the COVID-19 pandemic response on intrapartum care, stillbirth, and neonatal mortality outcomes in Nepal: a prospective observational study. Lancet Glob Heal.2020. https://doi.org/10.1016/ S2214-109X(20)30345-4. [PubMed] [Google Scholar]

29. COVID-19 and gender: What do we know; what do we need to know? UNWomen. Published 2020. Accessed August 15, 2020. [Link]

30. Women health workers: Working relentlessly in hospitals and at home. ILO. 2020. Accessed August 18, 2020. [Link]

31. COVID-19: The countries reporting the highest mental health declines. World Economic Forum. Published 2020. Accessed August 15, 2020. [Link]

32. Zeng L-N, Chen L-G, Yang C-M, Zeng L-P, Zhang L-Y, Peng T-M. Mental health care for pregnant women in the COVID-19 outbreak is urgently needed. Women Birth. May 2020. https://doi.org/10.1016/j.wombi.2020.03.009. [PubMed] [Google Scholar]

33. Topalidou A, Thomson G, Downe S. COVID-19 and maternal mental health: Are we getting the balance right? medRxiv. 2020. https://doi.org/10 $.1101 / 2020.03 .30 .20047969$. [Google Scholar]

34. Ali NA, Shahil Feroz A. Maternal mental health amidst the COVID-19 pandemic. Asian $J$ Psychiatr. 2020;54:102261. https://doi. org/10.1016/j.ajp.2020.102261. [PubMed] [Google Scholar]

35. Buekens P, Alger J, Bréart G, Cafferata ML, Harville E, Tomasso G. A call for action for COVID-19 surveillance and research during pregnancy. Lancet Glob Heal. 2020;8(7):e877-e878. https://doi.org/10.1016/ S2214-109X(20)30206-0. [Google Scholar] [PubMed] 
36. Gender and women's mental health. WHO. Accessed August 18, 2020. [Link]

37. Statement from the Executive Committee of the International Association for Suicide Prevention. IASP. https://www.iasp.info/. Published 2020. Accessed August 15, 2020. [Link]

38. Brådvik L. Suicide Risk and Mental Disorders. Vol. 15, International journal of environmental research and public health. 2018. https://doi. org/10.3390/ijerph15092028. [Google Scholar] [PubMed]

39. Sher L. The impact of the COVID-19 pandemic on suicide rates. QJM An Int J Med. 2020. https://doi.org/10.1093/qjmed/hcaa202. [Google Scholar][PubMed]
40. Children at increased risk of harm online during global COVID-19 pandemic - UNICEF. Unicef. 2020. Accessed August 18, 2020. [Link]

41. Media Consumption in the Age of COVID-19. J.P. Morgan. 2020. Accessed August 18, 2020. [Link]

42. Rising Levels of Hate Speech \& Online Toxicity During This Time of Crisis. Light. Published 2020. Accessed August 15, 2020.[Link]

43. Opinion: Don't let girls' education be another casualty of the coronavirus. GPE. Published 2020. Accessed August 15, 2020.[Link]

44. Education during COVID-19 and beyond. UN. Published 2020. Accessed August 15, 2020. [Link] 